\title{
Prenatal Smoking Exposure and the Risk of Behavioral Problems and Substance Use in Adolescence: the TRAILS Study
}

\author{
Karin Monshouwer ${ }^{a, b}$ Anja C. Huizink ${ }^{c, d}$ Zeena Harakeh ${ }^{a}$ \\ Quinten A.W. Raaijmakers ${ }^{e}$ Sijmen A. Reijneveld ${ }^{f} \quad$ Albertine J. Oldehinkel $^{g}$ \\ Frank C. Verhulst ${ }^{c}$ Wilma A.M. Vollebergh ${ }^{a}$

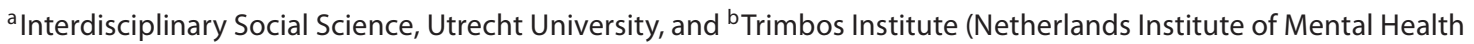 \\ and Addiction), Utrecht; ${ }^{C}$ Department of Child and Adolescent Psychiatry, Erasmus Medical Center, Rotterdam;

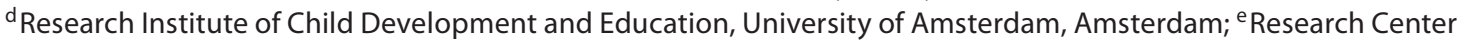 \\ Adolescent Development, Utrecht University, Utrecht; ${ }^{f}$ Department of Health Sciences and ${ }^{9}$ Interdisciplinary \\ Center for Psychiatric Epidemiology, Department of Psychiatry, University Medical Center Groningen, University of \\ Groningen, Groningen, The Netherlands
}

\section{Key Words}

Internalizing and externalizing behavioral problems • Prenatal smoking $\cdot$ Substance use in adolescence $\cdot$ TRAILS study

\begin{abstract}
Aims: To study the prospective relationship between maternal smoking during pregnancy (MSP) and behavioral problems, heavy alcohol use, daily smoking, and ever use of cannabis in the offspring, and to assess the role of confounding and mediating factors in a systematic way. Methods: Population-based cohort study of 2,230 respondents, starting in 2001 when respondents were around the age of 11 years, and two follow-up measurements at intervals of about 2.5 years (response rates of 96.0 and $81.4 \%$ ). Results: Almost one third of the respondents' mothers had smoked tobacco during pregnancy. These respondents were at an increased risk for all outcomes except internalizing problems (significant odds ratios ranged from 1.40 to 2.97 ). The successive models showed that the potential confounding factors reduced the strength of all relationships. In the full model, the strongest
\end{abstract}

relationship was found for mothers who smoked more than 10 cigarettes a day during pregnancy and daily smoking in early adolescence (odds ratio: 1.56), but none of the relationships were statistically significant. Conclusions: MSP is a marker for future behavioral outcomes in the offspring, but reducing the prevalence of MSP is unlikely to make a meaningful contribution to the prevention of these problems in adolescents.

Copyright $\odot 2011$ S. Karger AG, Basel

\section{Introduction}

It is well established that maternal smoking during pregnancy (MSP) can have detrimental effects on the fetus, in particular a low birth weight and preterm birth $[1$, 2]. In recent years a growing number of studies have focused on the effects of MSP during pregnancy on developmental and behavioral outcomes, reporting associations with a variety of symptoms and disorders in childhood and adolescence, including increased levels of attention deficit hyperactivity disorder (ADHD), exter-

\section{KARGER}

Fax +4161306 1234 E-Mail karger@karger.ch www.karger.com (c) 2011 S. Karger AG, Basel

1022-6877/11/0176-0342\$38.00/0

Accessible online at:

www.karger.com/ear
Karin Monshouwer

Interdisciplinary Social Science

Utrecht University, PO Box 80.140

NL-3508 TC Utrecht (The Netherlands)

Tel. +31 30253 9084, E-Mail k.monshouwer@uu.nl 
nalizing behavioral problems [3, 4], an increased risk of psychiatric and substance use disorders and even mortality in late adolescence and early adulthood [5]. The biological plausibility of the relationship is supported by animal studies which have indicated that in utero exposure to nicotine interferes with neuronal differentiation during fetal brain development [6].

If MSP is indeed found to be causally related to developmental or behavioral problems in the offspring, this would be an important public health issue. The potential for preventive activity would be large, as smoking during pregnancy is still common, with rates of $24 \%$ in Scotland, $17 \%$ in England [7], 13\% in Sweden, and 12\% in the United States [1]. However, there is still uncertainty with respect to causality of the observed relationship. Firstly, although the results of animal studies appear to be convincing, generalization from animal studies to humans is hampered by several factors, particularly differences between rats and humans in timing of brain maturation [6]. Secondly, as indicated by review studies, the research literature on observational studies in humans is not conclusive [6-8]. Methodological issues, in particular on how studies deal with confounding, are likely to explain part of these inconsistencies [6,9]. For example, low socioeconomic status, a maternal and paternal history of behavioral problems, smoking by the father, maternal smoking after pregnancy and maternal alcohol use during pregnancy are correlated with both MSP and developmental and behavioral problems in offspring $[1,6,7,10]$. Studies which do not adequately take these variables into account may overestimate the role of MSP in offspring developmental and behavioral outcomes.

In studying the effects of prenatal smoking, also mediating variables are of interest. Controlling the analyses for both type of variables may reduce the strength of the relationship between MSP and offspring outcomes. However, in the case of mediating variables, MSP still could have an effect on offspring outcomes through the indirect pathway, and may remain of relevance for prevention. For example, MSP is shown to be a risk factor for lower birth weight and complications during pregnancy and childbirth [1]. In turn, these variables have been linked to behavioral and developmental outcomes in offspring [1114]. However, the topic of mediation is scarcely addressed in the current research literature and studies have generally treated potential mediating variables as confounding variables [e.g. 5].

The aim of the present study is to assess the prospective relationship between MSP and behavioral outcomes in the offspring during early and middle adolescence and to as- sess the role of potential confounding and mediating factors in a systematic way. These factors include family socioeconomic status, parental (history of) internalizing and externalizing behavioral problems, maternal alcohol use during pregnancy, paternal and maternal smoking after childbirth, birth weight and complications during pregnancy and childbirth. Finally, while most other studies focused on externalizing behavioral problems and tobacco use, the present study additionally investigates the prospective association between MSP and alcohol and cannabis use, as well as internalizing behavioral problems.

\section{Method}

\section{Study Design and Population}

The present study is based on the data of the first, second and third waves of the TRacking Adolescents' Individual Lives Survey (TRAILS). Data collection at the first assessment started in 2001. The second and third assessment waves took place at intervals of about 2.5 years. Informed consent was obtained from all participants at each assessment wave. The Central Dutch Medical Ethics Committee has approved the study.

The target sample comprised young adolescents from five municipalities in the north of the Netherlands, including both urban and rural areas. The sample selection involved two steps. First, the municipalities were requested to provide names and addresses of all inhabitants born between 10 January 1989 and 30 September 1990 (first two municipalities) or between 1 October 1990 and 30 September 1991 (last three municipalities), which yielded 3,483 names. Simultaneously, primary schools within these municipalities were approached with a request to participate. Of the 135 schools, 122 (90.4\%) agreed to participate, accounting for $90.3 \%$ of the adolescents. Of all subjects approached $(n=3,145), 6.7 \%$ were excluded because of severe mental or physical handicap or language problems. Of the remaining 2,935 children, 2,230 (76.0\%) children and their parents agreed to participate, and all were included in the study (mean age 11.1 years, standard deviation $(\mathrm{SD})=0.6,50.8 \%$ female). Responders and non-responders did not differ with respect to the prevalence of teacher-rated problem behavior or the associations between sociodemographic variables and mental health indicators. A high response rate (96\%) was yielded at the second assessment $(n=2,149$, mean age 13.6 years, $\mathrm{SD}=0.5,51.2 \%$ female). On the third assessment $(\mathrm{n}=1,816$, mean age 16.3 years, $\mathrm{SD}=0.7,52.3 \%$ female), the response rate was somewhat lower (81.4\%). More details about the procedure have been published elsewhere [15].

\section{Procedure}

At the first assessment, well-trained interviewers visited one of the parents or guardians in their homes to administer an interview. In addition, the parent completed a written questionnaire. At the second and third assessment, parents were asked to fill out a questionnaire which they received by mail. At each of the three assessments, the self-report questionnaires were completed by the adolescent at school, in groups, supervised by a TRAILS assistant. Confidentiality of the study was emphasized. 


\section{Measures}

Outcome Variables. Externalizing and internalizing behavioral problems were assessed by the Youth Self Report (YSR) [16]. Good reliability and validity of this instrument were confirmed for the Dutch translation [17]. The YSR contains 101 problem items (3 categories: not true, somewhat true, very true or often true, on the basis of the preceding 6 months), of which 32 items measure externalizing and 31 items measure internalizing behavioral problems. Behavioral problems were defined as a score above the 90th percentile on the YSR, calculated for boys and girls separately and for both internalizing and externalizing problems [18]. Those scoring above the 90th percentile were coded as 1; all others were coded as 0 (no behavioral problems). Heavy alcohol use was based on questions concerning the average number of drinking days and average number of drinks on a drinking day, asked separately for weekdays (Monday to Thursday) and weekend days (Friday to Sunday). By multiplying the days and drinks for both the weekdays and the weekend days and adding these two figures, a total number of glasses per week was calculated. In order to determine a cut-off score for heavy alcohol use at T2 and T3, the authors assessed the group representing the $10 \%$ highest scores in our sample at T2 and T3, which showed a correlation with drinking 5 or more glasses of alcohol a week at T2 and 15 glasses or more at T3. This variable was coded as 1 (heavy alcohol use) and 0 (no heavy alcohol use). Daily tobacco use was measured by the question 'How many cigarettes did you smoke on average in the last 4 weeks ( 7 categories: never smoked, did not smoke in the last 4 weeks, $<1$ cigarette a day, $1-5,6-10,11-20,>20$ cigarettes a day). Those who reported smoking at least 1 cigarette a day (9\% at T2 and $29 \%$ at T3) were classified as daily smokers (coded as 1) and all other respondents were coded as 0 (not daily smokers). Lifetime cannabis use was assessed by the question 'How often in your life have you used weed or hashish? (14 categories, ranging from 0 to 40 times or more) [19]. Those who reported having used cannabis at least once (10\% at T2 and $40 \%$ at T3) were categorized as lifetime cannabis users (coded as 1) and all others were coded as 0 (never used cannabis).

Maternal Smoking during Pregnancy. MSP was assessed by asking the mother how many cigarettes she smoked during pregnancy ( 7 categories, ranging from none to more than 2 packs a day). In line with previous studies [4], this variable was recoded into 3 categories: no smoking (0), 1-10 cigarettes a day (1), and 11 cigarettes a day or more (2). A previous study on the same dataset, comparing these self-report data with data on MSP registered shortly after birth by Preventive Child Healthcare (data were available for a subset $(32 \%, \mathrm{n}=708)$ of the sample), indicated a high level of agreement between these reports $(\kappa=0.77)$ [20].

Covariates. All covariates were measured at wave 1 and were based on reports of one of the parents (96\% mothers) and included maternal age at childbirth, maternal alcohol use during pregnancy, family socioeconomic status (calculated as the average of income, educational, and occupational level of each parent at wave 1 [21]), daily smoking by the mother, daily smoking by the father and maternal/paternal (history) of internalizing and/or externalizing behavioral problems, birth weight, problems during pregnancy, problems during childbirth.

\section{Analyses}

Missing data were imputed by multiple imputation of missing data using bayesian analysis $[22,23]$ as implemented in Mplus
[24]. Ten imputed datasets were generated and parameter estimates were averaged over the set of analyses; standard errors were computed using the average of the standard errors over the set of analyses and the between-analysis parameter estimate variation $[22,23]$. All outcome variables were included in the model as dichotomous variables and analyzed using multiple logistic regression, resulting in odds ratios [25]. To assess whether the association between MSP and child outcomes holds up when confounding factors are taken into account, successive models were tested, each adding new potentially confounding variables to the previous model. In a final model, including all putative confounding factors, variables were added to the model in order to test mediation of the relationship between MSP and outcomes.

Studies have demonstrated that propensity scores are a better alternative to logistic regression analysis when there are seven or fewer outcome events per confounder $[26,27]$. Once there are eight or more outcome events per confounder, logistic regression analysis produces less bias, and performs similarly in terms of precision and slightly less, but sufficient, in terms of power [2628 ]. For the present study we estimated the number of outcome events per confounder in the most elaborate model (i.e. including 10 covariates) with the smallest number of outcome events (i.e. $9 \%$ for daily smoking at T2) and found that the number of events per variable was around 20 , indicating that logistic regression analysis is our preferred technique.

For reasons of comparability with previous studies, we dichotomized our outcome variables. The categorization of continues outcomes leads to a loss of information and the choice of cut-off score will influence the information and conclusions. However, additional analyses showed that identical conclusions resulted when linear regression models were fitted to test the relationship between prenatal smoking and externalizing and internalizing behavioral problems and zero-inflated Poisson regression models were fitted for alcohol use (number of glasses per week), cannabis use (frequency of lifetime use) and smoking (number of cigarettes a day).

All regression analyses were performed using PASW Statistics - SPSS 18.0 [29], except for the zero-inflated Poisson regression analyses which were performed using Mplus [24].

\section{Results}

The prevalence of MSP was substantial. Of all respondents, almost one third of their mothers had smoked cigarettes during pregnancy (table 1). Table 1 further shows that a low birth weight $(<2.5 \mathrm{~kg})$, was more prevalent among children of mothers who smoked more than 10 cigarettes a day (18.3\%). Mothers who smoked during pregnancy further appeared to more often come from low socioeconomic status families, to have frequently used alcohol during pregnancy (4 or more glasses of alcohol per week), to be daily smokers and to have husbands who were daily smokers in the year previous to T1. Finally, mothers who smoked cigarettes during pregnancy had higher scores on parental externalizing behavioral problems and, to a lesser extent, internalizing problems. 
Table 1. Maternal smoking during pregnancy by background factors

\begin{tabular}{|c|c|c|c|c|c|c|c|c|}
\hline \multirow[t]{3}{*}{ Background characteristics } & \multicolumn{8}{|c|}{ Maternal smoking during pregnancy } \\
\hline & \multicolumn{2}{|c|}{ total sample } & \multicolumn{2}{|c|}{0 cigarettes } & \multicolumn{2}{|c|}{$1-10$ cig./day } & \multicolumn{2}{|c|}{$>10$ cig./day } \\
\hline & $\mathrm{n}$ & $\%$ & $\mathrm{n}$ & $\%$ & $\mathrm{n}$ & $\%$ & $\mathrm{n}$ & $\%$ \\
\hline Total sample & 2,230 & 100 & 1,549 & 69.5 & 528 & 23.7 & 153 & 6.9 \\
\hline \multicolumn{9}{|l|}{ Maternal age at childbirth, years } \\
\hline$<20$ & 49 & 2.2 & 32 & 2.1 & 9 & 1.7 & 8 & 5.2 \\
\hline $20-34$ & 1,937 & 86.9 & 1,333 & 86.1 & 469 & 88.8 & 135 & 88.2 \\
\hline$\geq 35$ & 244 & 10.9 & 184 & 11.9 & 50 & 9.5 & 10 & 6.5 \\
\hline \multicolumn{9}{|l|}{ Gender } \\
\hline Male & 1,132 & 50.8 & 777 & 50.2 & 281 & 53.2 & 74 & 48.4 \\
\hline Female & 1,098 & 49.2 & 772 & 49.8 & 247 & 46.8 & 79 & 51.6 \\
\hline \multicolumn{9}{|l|}{ Birth weight, kg } \\
\hline$<1.5$ & 23 & 1.0 & 15 & 1.0 & 7 & 1.3 & 1 & 0.7 \\
\hline $1.5-2.5$ & 242 & 10.9 & 132 & 8.5 & 83 & 15.7 & 27 & 17.6 \\
\hline $2.5-4.0$ & 1,820 & 81.6 & 1,285 & 83.0 & 415 & 78.6 & 120 & 78.4 \\
\hline$\geq 4.0$ & 145 & 6.5 & 117 & 7.6 & 23 & 4.4 & 5 & 3.3 \\
\hline \multicolumn{9}{|l|}{ Problems during pregnancy } \\
\hline No & 1,657 & 74.3 & 1,141 & 73.7 & 404 & 76.5 & 112 & 73.2 \\
\hline Minor & 571 & 25.6 & 406 & 26.2 & 124 & 23.5 & 41 & 26.8 \\
\hline Severe & 2 & 0.1 & 2 & 0.1 & 0 & 0.0 & 0 & 0.0 \\
\hline \multicolumn{9}{|l|}{ Problems during childbirth } \\
\hline No & 1,332 & 59.7 & 913 & 58.9 & 314 & 59.5 & 105 & 68.6 \\
\hline Minor & 896 & 40.2 & 634 & 40.9 & 214 & 40.5 & 48 & 31.4 \\
\hline Severe & 2 & 0.1 & 2 & 0.1 & 0 & 0.0 & 0 & 0.0 \\
\hline \multicolumn{9}{|l|}{ Alcohol use during pregnancy } \\
\hline No use & 1,813 & 81.3 & 1,276 & 82.4 & 415 & 78.6 & 122 & 79.7 \\
\hline$<1$ glass/week & 311 & 13.9 & 217 & 14.0 & 80 & 15.2 & 14 & 9.2 \\
\hline 1-3 glasses/week & 80 & 3.6 & 50 & 3.2 & 22 & 4.2 & 8 & 5.2 \\
\hline 4-10 glasses/week & 24 & 1.1 & 6 & 0.4 & 11 & 2.1 & 7 & 4.6 \\
\hline$>10$ glasses/week & 2 & 0.1 & 0 & 0.0 & 0 & 0.0 & 2 & 1.3 \\
\hline \multicolumn{9}{|l|}{ Socioeconomic status of family } \\
\hline Low & 563 & 25.2 & 298 & 19.2 & 174 & 33.0 & 91 & 59.5 \\
\hline Medium & 1,105 & 49.6 & 787 & 50.8 & 266 & 50.4 & 52 & 34.0 \\
\hline High & 562 & 25.2 & 464 & 30.0 & 88 & 16.7 & 10 & 6.5 \\
\hline \multicolumn{9}{|l|}{ Daily smoking by mother at $\mathrm{T} 1$} \\
\hline No & 1,305 & 58.5 & 1,198 & 77.3 & 87 & 16.5 & 19 & 12.4 \\
\hline Yes & 925 & 41.5 & 351 & 22.7 & 441 & 83.5 & 134 & 87.6 \\
\hline \multicolumn{9}{|l|}{ Daily smoking by father at $\mathrm{T} 1$} \\
\hline No & 1,267 & 57.2 & 1,002 & 64.7 & 212 & 40.2 & 53 & 34.6 \\
\hline Yes & 963 & 43.2 & 547 & 35.3 & 316 & 59.8 & 100 & 65.4 \\
\hline \multicolumn{9}{|l|}{ Mean score } \\
\hline Parental internalizing problems & \multicolumn{2}{|c|}{0.558} & \multicolumn{2}{|c|}{0.515} & \multicolumn{2}{|c|}{0.634} & \multicolumn{2}{|c|}{0.726} \\
\hline Parental externalizing problems & \multicolumn{2}{|c|}{0.147} & \multicolumn{2}{|c|}{0.102} & \multicolumn{2}{|c|}{0.189} & & \\
\hline
\end{tabular}

Table 2 shows that in the unadjusted analyses (model 1) MSP is significantly associated with externalizing but not internalizing behavioral problems. The strongest association (odds ratio $(\mathrm{OR})=1.79,95 \%$ confidence inter$\operatorname{val}(\mathrm{CI})=1.32-2.43)$ is found for prenatal smoking of $1-10$ cigarettes a day and externalizing behavioral problems at
T2. Adding confounding factors in each of the successive models results in a decrease of the size of the ORs to 1.42 (1-10 cigarettes a day) and 1.18 (>10 cigarettes a day) for externalizing behavioral problems in the final model (both non-significant, i.e. $\mathrm{p}>0.05$ ). 
Table 2. Longitudinal associations between smoking behavior during pregnancy and externalizing and internalizing problems among adolescent offspring, in successive models, each adjusting for a different set of confounders ${ }^{\mathrm{a}}$

\begin{tabular}{|c|c|c|c|c|c|c|c|c|}
\hline \multirow[t]{3}{*}{ Number of cigarettes/day ${ }^{b}$} & \multicolumn{4}{|c|}{ Externalizing behavioral problems } & \multicolumn{4}{|c|}{ Internalizing behavioral problems } \\
\hline & \multicolumn{2}{|l|}{$\mathrm{T} 2$} & \multicolumn{2}{|l|}{$\mathrm{T} 3$} & \multicolumn{2}{|l|}{$\mathrm{T} 2$} & \multicolumn{2}{|l|}{ T3 } \\
\hline & OR & $95 \% \mathrm{CI}$ & OR & $95 \% \mathrm{CI}$ & OR & $95 \%$ CI & OR & $95 \% \mathrm{CI}$ \\
\hline \multicolumn{9}{|l|}{ Model 1} \\
\hline None & 1 & & 1 & & 1 & & 1 & \\
\hline $1-10$ cigarettes & $1.79 * * *$ & $1.32-2.43$ & $1.53^{*}$ & $1.03-2.26$ & 0.92 & $0.67-1.28$ & 1.14 & $0.78-1.68$ \\
\hline$>10$ cigarettes & $1.70^{*}$ & $1.05-2.77$ & 1.50 & $0.86-2.61$ & 1.43 & $0.88-2.33$ & 1.40 & $0.75-2.63$ \\
\hline \multicolumn{9}{|l|}{ Model 2} \\
\hline None & 1 & & 1 & & 1 & & 1 & \\
\hline $1-10$ cigarettes & $1.71^{*}$ & $1.25-2.34$ & 1.47 & $0.98-2.19$ & 0.89 & $0.64-1.24$ & 1.12 & $0.76-1.66$ \\
\hline$>10$ cigarettes & 1.59 & $0.95-2.67$ & 1.35 & $0.76-2.37$ & 1.36 & $0.81-2.29$ & 1.34 & $0.71-2.54$ \\
\hline \multicolumn{9}{|l|}{ Model 3} \\
\hline None & 1 & & 1 & & 1 & & 1 & \\
\hline $1-10$ cigarettes & $1.67^{* *}$ & $1.22-2.29$ & 1.43 & $0.95-2.14$ & 0.87 & $0.63-1.21$ & 1.11 & $0.75-1.64$ \\
\hline$>10$ cigarettes & 1.41 & $0.83-2.39$ & 1.19 & $0.66-2.15$ & 1.32 & $0.77-2.24$ & 1.33 & $0.70-2.55$ \\
\hline \multicolumn{9}{|l|}{ Model 4} \\
\hline None & 1 & & 1 & & 1 & & 1 & \\
\hline $1-10$ cigarettes & $1.56^{* *}$ & $1.12-2.16$ & 1.43 & $0.93-2.18$ & 0.87 & $0.62-1.23$ & 1.10 & $0.73-1.67$ \\
\hline$>10$ cigarettes & 1.30 & $0.75-2.25$ & 1.19 & $0.65-2.18$ & 1.32 & $0.77-2.28$ & 1.33 & $0.68-2.58$ \\
\hline \multicolumn{9}{|l|}{ Model 5} \\
\hline None & 1 & & 1 & & 1 & & 1 & \\
\hline $1-10$ cigarettes & 1.42 & $0.96-2.08$ & 1.39 & $0.83-2.33$ & 1.02 & $0.69-1.50$ & 1.28 & $0.81-2.03$ \\
\hline$>10$ cigarettes & 1.18 & $0.66-2.11$ & 1.16 & $0.59-2.56$ & 1.55 & $0.87-2.78$ & 1.55 & $0.74-3.25$ \\
\hline
\end{tabular}

${ }^{a}$ Model 1: unadjusted. Model 2: adjusted for maternal alcohol use during pregnancy, age mother at childbirth and socioeconomic status. Model 3: adds to model 2 parental history of internalizing problems, parental history of externalizing problems. Model 4: adds to model 3 paternal smoking at T1. Model 5: adds to model 4 maternal smoking at T1.

${ }^{b}$ None $(n=1,549), 1-10$ cigarettes a day $(n=528),>10$ cigarettes a day $(n=153)$.

${ }^{*} \mathrm{p}<0.05 ;{ }^{* *} \mathrm{p}<0.01 ;{ }^{* *} \mathrm{p}<0.001$.

Table 3 shows that in the unadjusted model (model 1), all substance use outcomes are significantly associated with MSP, except for heavy alcohol use at T3. The strongest association is found for mothers who smoked more than 10 cigarettes a day during pregnancy and daily smoking by the child at T2 $(\mathrm{OR}=2.97,95 \% \mathrm{CI}=1.84-$ 4.80). For the substance use outcomes, there appears to be a dose-effect relationship, i.e. the ORs are generally highest among those mothers who have smoked more than 10 cigarettes a day. Adding more potential confounding factors in each of the successive models, results in a strong decrease of the ORs. In the fifth model, when all confounding factors are included, the strength of the ORs varies between 1.56 and 0.85 , which are all statistically non-significant $(\mathrm{p}>0.05)$.

The tests for mediation are not performed, since mediation requires a significant association between the predictor and outcome variable, which appeared not to be the case for any of the outcome variables tested in the present study.

\section{Discussion}

This study has investigated the prospective relationship between smoking by the mother during pregnancy and outcomes of her offspring during early and middle adolescence and has systematically investigated the role of potentially confounding and mediating factors. Our findings suggest that children of mothers who smoke one or more cigarettes a day during pregnancy are at a higher risk for developing externalizing problems, becoming daily smokers, using cannabis and drinking heavily in adolescence. However, the inclusion of potentially con- 
Table 3. Longitudinal associations between smoking behavior during pregnancy and substance use among adolescent offspring, in successive models, each adjusting for a different set of confounders ${ }^{\mathrm{a}}$

\begin{tabular}{|c|c|c|c|c|c|c|c|c|c|c|c|c|}
\hline \multirow{3}{*}{$\begin{array}{l}\text { Number of } \\
\text { cigarettes/day }\end{array}$} & \multicolumn{4}{|c|}{ Daily smoking } & \multicolumn{4}{|c|}{ Ever use of cannabis } & \multicolumn{4}{|c|}{ Heavy alcohol use } \\
\hline & \multicolumn{2}{|l|}{$\mathrm{T} 2$} & \multicolumn{2}{|l|}{$\mathrm{T} 3$} & \multicolumn{2}{|l|}{$\mathrm{T} 2$} & \multicolumn{2}{|l|}{ T3 } & \multicolumn{2}{|l|}{$\mathrm{T} 2$} & \multicolumn{2}{|l|}{$\mathrm{T} 3$} \\
\hline & OR & $95 \%$ CI & OR & $95 \%$ CI & OR & $95 \%$ CI & OR & $95 \%$ CI & OR & $95 \%$ CI & OR & $95 \%$ CI \\
\hline \multicolumn{13}{|l|}{ Model 1} \\
\hline None & 1 & & 1 & & 1 & & 1 & & 1 & & 1 & \\
\hline $1-10$ cigarettes & $2.14^{* * *}$ & $1.49-3.07$ & $1.71^{* * *}$ & $1.34-2.20$ & $1.45^{*}$ & $1.02-2.05$ & $1.40^{*}$ & $1.12-1.76$ & $1.58^{* *}$ & $1.13-2.20$ & 1.43 & $0.91-2.24$ \\
\hline$>10$ cigarettes & $2.97^{* * *}$ & $1.84-4.80$ & $1.71^{* * *}$ & $1.16-2.52$ & $1.76^{*}$ & $1.03-3.01$ & $1.54^{*}$ & $1.06-2.23$ & $1.90^{*}$ & $1.14-3.16$ & 1.71 & $0.99-2.97$ \\
\hline \multicolumn{13}{|l|}{ Model 2} \\
\hline None & 1 & & 1 & & 1 & & 1 & & 1 & & 1 & \\
\hline $1-10$ cigarettes & $1.98^{* * *}$ & $1.43-2.76$ & $1.54^{* * *}$ & $1.18-2.00$ & 1.39 & $0.97-1.99$ & $1.36^{*}$ & $1.07-1.71$ & $1.46^{*}$ & $1.04-2.06$ & 1.32 & $0.84-2.08$ \\
\hline$>10$ cigarettes & 2.60 & $1.62-4.17$ & 1.29 & $0.87-1.91$ & 1.64 & $0.94-2.87$ & 1.45 & $0.99-2.12$ & 1.58 & $0.93-2.68$ & 1.40 & $0.80-2.48$ \\
\hline \multicolumn{13}{|l|}{ Model 3} \\
\hline None & 1 & & 1 & & 1 & & 1 & & 1 & & 1 & \\
\hline 1-10 cigarettes & $1.85^{* * *}$ & $1.27-2.69$ & $1.50^{* * *}$ & $1.15-1.96$ & 1.33 & $0.92-1.92$ & $1.34^{*}$ & $1.05-1.70$ & $1.43^{*}$ & $1.01-2.01$ & 1.32 & $0.84-2.10$ \\
\hline$>10$ cigarettes & $2.01^{* *}$ & $1.19-3.41$ & 1.18 & $0.78-1.77$ & 1.34 & $0.75-2.41$ & 1.37 & $0.93-2.01$ & 1.43 & $0.83-2.46$ & 1.44 & $0.80-2.58$ \\
\hline \multicolumn{13}{|l|}{ Model 4} \\
\hline None & 1 & & 1 & & 1 & & 1 & & 1 & & 1 & \\
\hline $1-10$ cigarettes & $1.70^{* *}$ & $1.15-2.52$ & $1.33^{*}$ & $1.01-1.75$ & 1.29 & $0.88-1.88$ & 1.25 & $0.97-1.61$ & 1.34 & $0.94-1.89$ & 1.24 & $0.78-1.97$ \\
\hline$>10$ cigarettes & $1.83^{*}$ & $1.06-3.15$ & 1.02 & $0.67-1.55$ & 1.30 & $0.71-2.38$ & 1.26 & $0.85-1.89$ & 1.32 & $0.77-2.28$ & 1.34 & $0.75-2.39$ \\
\hline \multicolumn{13}{|l|}{ Model 5} \\
\hline None & 1 & & 1 & & 1 & & 1 & & 1 & & 1 & \\
\hline $1-10$ cigarettes & 1.46 & $0.95-2.25$ & 1.12 & $0.83-1.50$ & 1.17 & $0.76-1.80$ & 1.07 & $0.79-1.45$ & 1.18 & $0.79-1.77$ & 1.17 & $0.68-2.00$ \\
\hline$>10$ cigarettes & 1.56 & $0.88-2.78$ & 0.85 & $0.54-1.35$ & 1.18 & $0.63-2.21$ & 1.08 & $0.71-1.65$ & 1.17 & $0.66-2.07$ & 1.26 & $0.68-2.32$ \\
\hline
\end{tabular}

a Model 1: unadjusted. Model 2: adjusted for maternal alcohol use during pregnancy, age mother at childbirth and socioeconomic status. Model 3: adds to model 2 parental history of internalizing problems, parental history of externalizing problems. Model 4: adds to model 3 paternal smoking at T1. Model 5: adds to model 4 maternal smoking at T1.

${ }^{\mathrm{b}}$ None $(\mathrm{n}=1,549), 1-10$ cigarettes a day $(\mathrm{n}=528),>10$ cigarettes a day $(\mathrm{n}=153)$.

${ }^{*} \mathrm{p}<0.05 ;{ }^{* *} \mathrm{p}<0.01 ;{ }^{* * *} \mathrm{p}<0.001$.

founding variables lowered the strength of the relationship to ORs varying between 0.85 and 1.56 in the full model, which were all statistically non-significant $(\mathrm{p}>$ $0.05)$.

These results are based on a large $(n=2,230)$ population-based cohort study, comprising multiple informants (adolescent and parent reporting), including data on a wide range of background characteristics and using a validated instrument to assess child psychopathology (i.e. the YSR) [16] which has been widely used and shown to be highly predictive of disorders at later ages (based on the Diagnostic and Statistical Manual of Mental Disorders (DSM)). Furthermore, by using self-report and not parent reported data for the outcome measures, there was no risk of information bias induced by awareness among the parents that smoking during pregnancy could have had adverse effects on their child. Finally, the findings appeared to be robust as including the outcome variables as continues/count variables in the analyses led to similar conclusions as the analyses on the dichotomized outcome variables.

The findings of our study demonstrate the important role of confounding factors in the relationship between MSP and offspring's risk for behavioral problems, i.e. the strength of all relationships decreased substantially when potentially confounding factors were included in the model. These findings are in line with a number of recent quasi-experimental studies, comparing siblings differentially exposed to MSP, concluding that familial background factors and not the specific exposure to MSP account for the associations between MSP and offspring behavioral outcomes [30-33]. The fact that a substantial number of studies [3,34-37], including a recent, welldesigned and powered birth cohort study in Finland [5], concluded that MSP increases the risk for offspring behavioral problems, is most likely explained by the fact that these studies did not adequately address the issue of confounding. For example, almost none of the studies 
concluding that MSP increases the risk for externalizing behavioral problems [3, 5, 35-37] controlled for mothers' and fathers' smoking patterns after the birth of their child. Additionally, studies did not take into account family socioeconomic status and paternal psychiatric morbidity [5] or parental psychiatric morbidity [37], while Fergusson et al. [3] accounted for parental criminal behavior but not for other types of parental psychiatric morbidity. A Dutch birth cohort study appeared to account for all relevant confounding factors, but did not use a standardized and validated instrument to assess externalizing behavioral problems [34]. In line with the results of the present study, a population-based study in Sweden, comparing siblings differentially exposed to prenatal smoking, demonstrated that the association between maternal smoking in pregnancy and offspring criminality was fully accounted for by familial background factors [38]. Boutwell and Beaver [39], using a propensity scorematching analysis, concluded that the relationship between smoking during pregnancy and externalizing behavioral problems was spurious. Roza et al. [40] demonstrated that the relationship between MSP and child behavior problems was fully accounted for by family socioeconomic status and parental psychopathology. Convincing evidence for the role of inheritable pathways was reported by Rice et al. [41], comparing the association between MSP and antisocial behavior in the offspring of mothers who were either biologically related or unrelated to their child as a result of in vitro fertilization. The authors concluded that the relationship was entirely explained by inherited pathways, as the offspring of mothers who smoked during pregnancy and were biologically related to their child were at higher risk for conduct problems, while such an effect was not found in the offspring of mothers who smoked during pregnancy but were biologically unrelated to their child [41]. Based on a longitudinal twin study, it was concluded that around half of the observed association between MSP and young children's conduct problems was attributable to correlated genetic effects [42]. Additional control for environmental risks reduced the initial effect of MSP by $75-100 \%$ [32]. D'Onofrio et al. [38], comparing siblings differentially exposed to MSP, concluded that familial background factors and not the specific exposure to MSP account for the associations between MSP and offspring disruptive behaviors.

In line with most previous studies $[3,34,37,40]$ the authors did not find evidence for an association between MSP and internalizing problems in the offspring. Jaspers et al. [43], using data from the first wave of the TRAILS study when respondents were around the age of 11, found a weak, but significant relationship between MSP and internalizing problems. A Dutch study concluded that prenatal smoking was related to increased levels of internalizing problem from ages 5 to 18 years [44]. Furthermore, Robinson et al. [36] found an association with higher scores on the internalizing scale of the Child Behavior Check List (CBCL), but not with clinically meaningful internalizing behavioral problems. None of these studies $[36,43,44]$ controlled for mothers' and fathers' smoking patterns after the birth of their child.

Relatively few studies have investigated the relationship between MSP and offspring's substance use patterns, mainly with regard to smoking. Buka et al. [45] showed that the offspring of mothers who smoked one pack or more a day during pregnancy had a greater likelihood of becoming nicotine-dependent as adults, but not of ever smoking or becoming a regular smoker. Fergusson et al. [3] found no relationship between MSP and nicotine dependence in late adolescence. There is preliminary evidence that MSP may affect offspring smoking behavior through an indirect pathway $[46,47]$. Children with prenatal exposure to maternal smoking had higher ADHD symptom scores and were not susceptible to the positive impact of an intervention on the course of their ADHD symptoms and on the probability of early-onset experimentation with smoking $[46,47]$. A few studies tried to disentangle the effect of pregnancy smoking and nonpregnancy smoking on the smoking behavior of the children $[48,49]$. The general conclusion of these studies was that both pregnancy smoking and non-pregnancy smoking were associated with an elevated risk for regular smoking in their offspring, with smoking during pregnancy constituting an additional risk. Perhaps the inability to quit smoking during and after pregnancy reflects a genetic vulnerability for nicotine addiction in these mothers, which is passed down to their children. Studies on the relationship between MSP and substance use other than tobacco are scarce and their focus is on abuse and dependency in their offspring and not on use as in the present study. The study of Ekblad et al. [5] found a relationship between MSP and ICD-10 diagnoses due to substance use, but as discussed earlier, these findings may be (partly) explained by incomplete adjustment for confounding factors. Nomura et al. [50] found that the adult offspring of mothers who smoked 20 cigarettes a day or more were at greater risk for a lifetime diagnoses for alcohol use disorders, but the magnitude of the effect was modest. Fergusson et al. [3] found no relationship with illicit substance use or dependency in late adolescence. 
Similarly, Buka et al. [45] concluded that the odds of marijuana dependence were not significantly elevated among the offspring of mothers who smoked during pregnancy.

The present study has some limitations. First, the measure of smoking during pregnancy was asked retrospectively which may have resulted in recall bias. However, a previous study on the same dataset [20] and other studies [e.g. 51] have indicated that the strength of agreement between maternal report and antenatal medical records of MSP is good. Second, the measure of MSP was not very precise in measuring in utero tobacco smoke exposure, as it was not known if the reported number of cigarettes a day was stable over the entire pregnancy period. Therefore, we were unable to address the possible effects of the timing of MSP on the child outcomes. Third, although this study is among the few to take into account the smoking behavior of the mother and father after the birth of their child, the parental smoking measure only referred to smoking in the year prior to the first measurement, so information on parental smoking in the period from birth to around the age of 10 was not available.

In conclusion, MSP is a marker for future externalizing behavioral and substance use problems in the adolescent offspring, but the results of the present study do not suggest that the relationship is causal. Other, correlated parental factors (e.g. parental behavioral problems and parental smoking after the birth of the child) appear to explain an important part of the observed relationship between MSP and offspring behavioral and substance use outcomes. Reducing the prevalence of smoking during pregnancy is therefore unlikely to make a meaningful contribution to the prevention of these problems in adolescents.

\section{Acknowledgements}

This research is part of the TRacking Adolescents' Individual Lives Survey (TRAILS). Participating centers of TRAILS include various departments of the University Medical Center and University of Groningen, the Erasmus University Medical Center Rotterdam, the University of Utrecht, the Radboud Medical Center Nijmegen, and the Parnassia Bavo group, all in the Netherlands. TRAILS has been financially supported by various grants from the Netherlands Organization for Scientific Research NWO (Medical Research Council program grant GB-MW 940-38-011; ZonMW Brainpower grant 100-001-004; ZonMw Risk Behavior and Dependence grants 60-60600-98-018 and 60-60600-97-118; ZonMw Culture and Health grant 261-98-710; Social Sciences Council medium-sized investment grants GB-MaGW 480-01006 and GB-MaGW 480-07-001; Social Sciences Council project grants GB-MaGW 457-03-018, GB-MaGW 452-04-314, and GB-MaGW 452-06-004; NWO large-sized investment grant 175.010.2003.005; NWO Longitudinal Survey and Panel Funding 481-08-013); the Sophia Foundation for Medical Research (projects 301 and 393), the Dutch Ministry of Justice (WODC), the European Science Foundation (EuroSTRESS project FP-006), and the participating universities. We are grateful to all adolescents, their parents and teachers who participated in this research and to everyone who worked on this project and made it possible.

\section{References}

1 Cnattingius S: The epidemiology of smoking during pregnancy: smoking prevalence, maternal characteristics, and pregnancy outcomes. Nicotine Tob Res 2004;6:S125-S140.

$\checkmark 2$ Winklbaur B, Baewert A, Jagsch R, Rohrmeister K, Metz V, Aeschbach Jachmann C, Thau K, Fischer G: Association between prenatal tobacco exposure and outcome of neonates born to opioid-maintained mothers. Implications for treatment. Eur Addict Res 2009;15:150-156.

- 3 Fergusson DM, Woodward LJ, Horwood LJ: Maternal smoking during pregnancy and psychiatric adjustment in late adolescence. Arch Gen Psychiatry 1998;55:721-727.

-4 Huizink AC, Mulder EJH: Maternal smoking, drinking or cannabis use during pregnancy and neurobehavioral and cognitive functioning in human offspring. Neurosci Biobehav Rev 2006;30:24-41.
5 Ekblad M, Gissler M, Lehtonen L, Korkeila J: Prenatal smoking exposure and the risk of psychiatric morbidity into young adulthood. Arch Gen Psychiatry 2010;67:841-849.

6 6 Huizink AC: Moderate use of alcohol, tobacco and cannabis during pregnancy: new approaches and update on research findings. Reprod Toxicol 2009;28:143-151.

7 Shipton D, Tappin DM, Vadiveloo T, Crossley JA, Aitkin DA, Chalmers JJ: Reliability of self-reported smoking status by pregnant women for estimating smoking prevalence: a retrospective cross sectional study. BMJ 2009;339:b4347.

-8 Linnet KM, Dalsgaard S, Obel C, Wisborg K, Henriksen TB, Rodrigues A, Kotimaa A, Moilanen I, Thomsen RH, Olsen J, Jarvelin MR: Maternal lifestyle factors in pregnancy risk of attention deficit hyperactivity disorder and associated behaviors: review of the current evidence. Am J Psychiatry 2003;160: 1028-1040.
9 Knopnik VS: Maternal smoking during pregnancy and child outcomes: real or spurious effect? Dev Neuropsychol 2009;34:1-36.

10 Wakschlag LS, Pickett KE, Cook E, Benowitz NL, Leventhal BL: Maternal smoking during pregnancy and severe antisocial behavior in offspring: a review. Am J Public Health 2002; 92:967-974

-11 Alati R, Najman JM, O'Callaghan M, Bor W, Williams GM, Clavarino AA: Fetal growth and behaviour problems in early adolescence: findings from the Mater University Study of Pregnancy. Int J Epidemiol 2009;38: 1390-1400.

12 Reijneveld SA, De Kleine MJK, Van Baar AL, Kollée LAA, Verhaak CM, Verhulst FC, Verloove-Vanhorick SP: Behavioral and emotional problems in very preterm and very low birth weight infants at age 5 years. Arch Dis Child Fetal Neonatal Ed 2006;91:423-428. 
$\checkmark 13$ Huizink AC, Robles de Medina PG, Mulder EJH, Visser, GHA, Buitelaar JK: Stress during pregnancy is associated with developmental outcome in infancy. J Child Psychol Psychiatry 2003;44:810-818.

- 14 Mulder EJH, Robles de Medina PG, Huizink AC, Van den Bergh BRH, Buitelaar JK, Visser GHA: Prenatal maternal stress: effects on pregnancy and the (unborn) child. Early Hum Dev 2002;70:3-14.

-15 De Winter AF, Oldehinkel AJ, Veenstra R, Brunnekreef JA, Verhulst FC, Ormel J: Evaluation of non-response bias in mental health determinants and outcomes in a large sample of pre-adolescents. Eur J Epidemiol 2005; 20:173-181.

16 Achenbach TM: Manual for the Youth SelfReport and 1991 Profile. Burlington, University of Vermont, Department of Psychiatry, 1991.

17 Verhulst FC, Van der Ende J, Koot HM: Manual for the Youth Self-Report (in Dutch). Rotterdam, Erasmus University Rotterdam, 1997.

18 Steinhausen HC, Halimeier C, Winkler Metzke C: Psychosocial factors in adolescent and young adult self-reported depressive symptoms: causal or correlational associations? J Youth Adolesc 2007;36:89-100.

19 O'Malley P, Bachman JG, Johnston LD: Reliability and consistency in self-reports of drug use. Int J Addict 1983;18:805-824.

-20 Jaspers M, De Meer G, Verhulst FC, Ormel J, Reijneveld SA: Limited validity of parental recall on pregnancy, birth, and early childhood at child age 10 years. J Clin Epidemiol 2010;63:185-191.

21 Ganzeboom HBG, Treiman DJ: Internationally comparable measures of occupational status for the 1988 International Standard Classification of Occupations. Soc Sci Res 1996:25:201-239.

22 Rubin DB: Multiple Imputation for Nonresponse in Surveys. New York, Wiley, 1987.

23 Schafer JL: Analysis of Incomplete Multivariate Data. London, Chapman \& Hall, 1997.

24 Muthén LK, Muthén BO: Mplus User's Guide, ed 6. Los Angeles, Muthén \& Muthén, 2010.

25 Bland JM, Altman DG: Statistical notes. The odds ratio. BMJ 2000;320:1468.

-26 Biondi-Zoccai G, Romagnoli E, Agostoni P, Capodanno D, Castagno D, D’Ascenzo F, Sangiorgi G, Modena MG: Are propensity scores really superior to standard multivariable analysis? Contemp Clin Trials 2011;32: 731-740.

-27 Cepeda M, Boson R, Farrar JT, Storm BL: Comparison of logistic regression versus propensity score when the number of events is low and there are multiple confounders. Am J Epidemiol 2003;158:280-287.

-28 Peduzzi P, Concato J, Kemper E, Holford TR, Feinstein AR: A simulation study of the number of events per variable in logistic regression analysis. J Clin Epidemiol 1996;49: 1373-1379.
29 IBM Corporation: PASW Statistics - SPSS 18.0. Somers, IBM Corp, 2010.

30 D’Onofrio BM, Singh AL, Iliadou A, Lambe M, Hultman CM, Grann M, Neiderhiser JM, Långström N, Lichtenstein P: Familial confounding of the association between maternal smoking during pregnancy and offspring criminality: a population-based study in Sweden. Arch Gen Psychiatry 2010;67:529-538.

31 D'Onofrio BM, Singh AL, Iliadou A, Lambe M, Hultman CM, Neiderhiser JM, Långström N, Lichtenstein P: A quasi-experimental study of maternal smoking during pregnancy and offspring academic achievement. Child Dev 2010;81:80-100.

32 Lindblad F, Hjern A: ADHD after fetal exposure to maternal smoking. Nicotine Tob Res 2010;12:408-415.

-33 Lundberg F, Cnattingius S, D’Onofrio B, Altman D, Lambe M, Hultman C, Iliadou A: Maternal smoking during pregnancy and intellectual performance in young adult Swedish male offspring. Paediatr Perinat Epidemiol 2010;24:79-87.

34 Batstra L, Hadders-Algra M, Neeleman J: Effect of antenatal exposure to maternal smoking on behavioral problems and academic achievement in childhood: prospective evidence from a Dutch birth cohort. Early Hum Dev 2003;75:21-33.

35 Buschgens CJM, Swinkels SHN, Van Aken MAG, Ormel J, Verhulst FC, Buitelaar JK: Externalizing behaviors in preadolescents: familial risk to externalizing behaviors, prenatal and perinatal risk, and their interactions. Eur Child Adolesc Psychiatry 2009;18: 65-74.

36 Robinson M, McLean NJ, Oddy WH, Mattes E, Bulsara M, Li J, Zubirck SR, Stanley FJ, Newnham JP: Smoking cessation in pregnancy and the risk of child behavioral problems: a longitudinal prospective cohort study. J Epidemiol Community Health 2010; 64:622-629.

37 Brion MJ, Victora C, Matijasevich A, Horta B, Anselmi L, Steer C, Menezes AMB, Lawlor DA, Davey Smith G: Maternal smoking and child psychological problems: disentangling causal and noncausal effects. Pediatrics 2010;126:e57-e65.

38 D’Onofrio BM, Singh AL, Iliadou A, Lambe M, Hultman CM, Grann M, Neiderhiser JM, Langström N, Lichtenstein P: Familial confounding of the association between maternal smoking during pregnancy and offspring criminality. A population-based study in Sweden. Arch Gen Psychiatry 2010;67:529538.

39 Boutwell BB, Beaver KM: Maternal cigarette smoking during pregnancy and offspring externalizing problems: a propensity score matching analysis. Int J Environ Res Public Health 2010;6:146-163.
40 Roza SJ, Verhulst FC, Jaddoe VWV, Steegers EAP, Mackenbach JP, Hofman A, Tiemeier $\mathrm{H}$ : Maternal smoking during pregnancy and child behavior problems: the Generation $\mathrm{R}$ Study. Int J Epidemiol 2009;38:680-689.

41 Rice F, Harold GT, Botvin J, Hay DF, Van den Bree M, Thapar A: Disentangling prenatal and inherited influences in humans with an experimental design. Proc Natl Acad Sci USA 2009; 106:2464-2467.

42 Maughan G, Taylor A, Caspi A, Moffitt TE: Prenatal smoking and early childhood conduct problems. Arch Gen Psychiatry 2004; 61:836-843.

$\checkmark 43$ Jaspers M, De Winter F, De Meer G, Stewart RE, Verhulst FC, Ormel J, Reijneveld SA: Early findings of preventive child healthcare professionals predict psychosocial problems in preadolescence: the TRAILS Study. J Pediatr 2010;157:316-321.

44 Ashford J, Van Lier PAC, Timmermans M, Cuijpers P, Koot HM: Prenatal smoking and internalizing and externalizing problems in children studied from childhood to late adolescence. J Am Acad Child Adolesc Psychiatry 2008;47:779-787.

45 Buka SL, Shenass ED, Niaura R: Elevated risk of tobacco dependence among offspring of mothers who smoked during pregnancy: a 30-year prospective study. Am J Psychiatry 2003;160:1978-1984.

46 Huizink AC, van Lier PAC, Crijnen AAM: Attention deficit hyperactivity disorder symptoms mediate early-onset smoking. Eur Addict Res 2009;15:1-9.

47 Vuijk P, van Lier PAC, Huizink AC, Verhulst FC, Crijnen AA: Prenatal smoking predicts non-responsiveness to an intervention targeting attention-deficit/hyperactivity symptoms in elementary schoolchildren. J Child Psychol Psychiatry 2006;47:891-901.

48 Mamun AA, O'Callaghan FV, Alati R, O'Callaghan M, Najman JM, Williams GM, Bor W: Does maternal smoking during pregnancy predict the smoking patterns of young adult offspring? Tob Control 2006;15:452457.

49 Lieb R, Schreier A, Pfister H, Wittchen HU: Maternal smoking and smoking in adolescents: a prospective community study of adolescents and their mothers. Eur Addict Res 2003;9:120-130.

50 Nomura Y, Gilman SE, Buka SL: Maternal smoking during pregnancy and risk of alcohol use disorders among adult offspring. J Stud Alcohol Drugs 2011;72:199-209.

51 Rice F, Lewis A, Harold G, Van den Bree M, Boivin J, Hay DF, Owen HJ, Thapar A: Agreement between maternal report and antenatal records for a range of pre- and perinatal factors: the influence of maternal and child characteristics. Early Hum Dev 2007; 83:497-504. 